\title{
DOES THE RIGHT TO ACCESS TO HEALTH CARE SERVICES IN TERMS OF SECTION 27 OF THE CONSTITUTION OF SOUTH AFRICA, 1996 CATER FOR CANCER PATIENTS?
}

\author{
Charles Maimela \\ LLB LLM \\ Lecturer, Department of Private Law \\ University of Pretoria
}

\section{SUMMARY}

Does the right to health care services as provided in terms of the Constitution of the Republic of South Africa, cater for cancer patients due to the expensive nature of cancer treatment and, if so, to what extent? One of the major socio-economic rights which cancer patients struggle to access is the right to health care services, which is currently dependent on the economic or financial position of a cancer patient, which is, unfortunately, the deciding factor in South Africa as well the entire continent of Africa. The financial or economic standing of a patient or a cancer patient, in this case, will determine if the patient will receive adequate cancer treatment or not. Does the economic or financial position of the cancer patient serve as a valid and justifiable reason for the right to access to health care services to the 75 per cent of people in South Africa who rely on public health care services for different health deformities that include cancer and, if so, to what extent?

INTRODUCTION

People who are diagnosed with cancer are entitled to medical treatment and rehabilitation from cancer. This forms part of the right to access to health care services as enshrined in terms of section 27 of the Constitution of the Republic of South Africa, $1996 .{ }^{1}$ Therefore, cancer patients can seek health services from health establishments in order to deal with cancer, as this forms part of their right to access to health care as protected by the Constitution. An in-depth analysis with regards to the right to health care services in the context of cancer patients forms the basis of this paper. However, this paper will not be complete if a reference to the basic

Hereinafter "the Constitution". The Constitution guarantees the right to have access to health care services, which includes reproductive health care to everyone as a basic and fundamental right that is enjoyed by every person in terms of Section 27 of the Constitution. 
understanding of cancer is not outlined. This will be to define what cancer is and how it develops in the human body as the first point of reference. After this background analysis of cancer, focus will revert back to the main objective of this paper, which is to assess the right of cancer patients to access health care services as protected by the Constitution. This will be done by analysing how public and private health establishments administer health care services to the members of the public and their role in ensuring that the right to health care services is administered to a patient and in this case the cancer patient.

\section{THE MEANING OF CANCER}

As a point of departure, it is essential to look at the definition of the term "cancer". In the $12^{\text {th }}$ century, Hippocrates, who was also known as the "Father of Medicine", discovered cancer. ${ }^{2}$ Cancer is defined as a process where cells in the body grow in an uncontrollable way. ${ }^{3}$ The word cancer is derived from the Latin word "crab", which describes the way in which cancer spreads or appears in the human body, and which has a crab-like appearance. ${ }^{4}$ These include cancers from covering tissues, skin cancer, mucous membrane cancer and cancer of the glands. ${ }^{5}$ Further, the Regulations Relating to Cancer Registration, ${ }^{6}$ define cancer as all malignant neoplasms and conditions suspected to be such, as contained in the International Classifications of Diseases for Oncology. ${ }^{7}$ Another word used to describe cancer is "sarcoma" which is the type of cancer that targets supporting body structures such as the bones, tendons, muscles and fibrous tissues. $^{8}$

From these definitions, it becomes clear that cancer can spread throughout the human body to an extent where it is uncontrollable and unmanageable. One can be sure that cancer is indeed a very dangerous disease, which affects all of humankind without prejudice. ${ }^{9}$ However, because of its complex nature, new knowledge is discovered daily and there

\footnotetext{
Barrow "Portraits of Hippocrates" 200123 Medical History 86.

Friedberg Cancer Answers (1993) 2.

David Cancer Care (1995) 2.

Scott Principles and Applications of Assessment in Counselling (2013) 314.

6 Regulations Relating to Cancer Registration GN R380 in GG 34248 issued in terms of the National Health Act 61 of 2003 dated 26 April 2011.

S 1 of the National Health Act 61 of 2003.

Heney, Young and Dixon-Woods Rethinking Experiences of Childhood Cancer (2005) 21.

9 Carnevali and Reiner The Cancer Experience (1990) 1. Further, it is a reasonable argument and an unfortunate fact that nearly anyone across the globe has had his or her life touched by cancer to a lesser or greater extent, such as they themselves being affected by cancer directly; or indirectly, having a family member or loved one affected by cancer. Cancer is a disease that preys on all of us; both young and old people are affected. Cancer holds no respect for national boundaries, ethnicity, race and social class because all of us are equal when it comes to the epidemic of cancer. Striking as much from within as without, cancer damages our individual and collective sense of health and well-being, and thus forms an integral part of our whole life. This is due to the fact that its human and economic effects are potent, measured each year in millions of productive years lost and billions of health care money spent. Cancer is a fearsome adversary, leaving tragedy in its wake; as we can see today cancer is the reason why millions of lives are lost annually. See Greenwald, David and Scott Cancer Prevention and Control (2001) 9.
} 
is still a lot to be learned about cancer, both in the medical profession and society in general. ${ }^{10}$

\section{CANCER TREATMENT IN THE CONTEXT OF THE RIGHT TO ACCESS TO HEALTH CARE SERVICES}

Section 27(1) of the Constitution guarantees everyone the right to access to health care services, which includes reproductive health care, and that no one may be refused emergency medical treatment. The government has a duty to fulfil this obligation to provide health services to the people based on the reasonable availability of resources; including the private health care sector, to a greater or lesser extent, particularly in emergency medical treatment. ${ }^{11}$ This means that if health practitioners deny people medical treatment or emergency medical treatment, their actions would amount to a violation of the right to access to health care as protected by the Constitution. Violating socio-economic rights, which are guaranteed in the Constitution, will go against the purpose for which these rights were designed because chapter two of the Constitution is aimed at addressing the imbalances and injustices of the past. ${ }^{12}$ Further, to deny or violate socioeconomic rights will constitute a contravention of section 7(2) of the Constitution, which states that the government must respect, promote, protect and fulfil the rights in the Bill of Rights. ${ }^{13}$ This provision clearly outlines the duty of government not only to refrain from interfering with the enjoyment of these rights, but it must also promote, protect and enhance their realisation as part of its constitutional mandate.

The debate as to whether socio-economic rights are justiciable or not, has long been settled in the South African context, as this is evident from the torch-bearing decisions delivered by the courts in cases such as the Soobramoney $v$ Minister of Health, KwaZulu-Natal case, for instance. ${ }^{14}$ In this paper, reference will not be made to the debate about the justiciability of

Carnevali and Reiner The Cancer Experience (1990) 2.

S 27(2) of the Constitution.

12 Chapter Two of the Constitution contains the Bill of Rights and a human rights charter that aims for the protection of civil, political and socio-economic rights of all the people in South Africa. The rights in the Bill of Rights apply to all laws, including common law, and bind all the branches of government including the executive, legislative, judiciary, provincial governments and municipal councils across the Republic.

13 Section 7(2) of the Constitution states that the state must protect, respect, promote and fulfil the rights in the Bill of Rights. Further, it is important to take into account that the inclusion of a comprehensive Bill of Rights on the final Constitution of the Republic of South Africa, 1996 has fundamentally influenced the law and its application in general in South Africa. The Bill of Rights enshrines the fundamental rights of all people in South Africa, and obliges or compels the government to respect, promote and fulfil such rights. The aim or objective of the Bill of Rights is to protect the individual or person, who is generally in a subordinate position with the government against its excessive power. One can say that the role of the Bill of Right is to prevent the arbitrary limitation, infringement and curtailment of people's rights and prescribes strict requirements for the lawful limitation of such rights by the government. See further, Bekink Principles of South African Constitutional Law (2012) 181.

14 Soobramoney $v$ Minister of Health, KwaZulu-Natal 1998 (1) SA 765 (CC). 
socio-economic rights, but focus will be placed on the role of the courts in protecting socio-economic rights, such as the right to access to health care. Brand argues that the courts can enforce socio-economic rights in two ways; firstly through their law-making powers of interpreting legislation and developing the rules of common law and secondly, the courts ought to adjudicate constitutional and other challenges experienced in state procedures, which are intended to advance socio-economic rights. ${ }^{15}$ The interpretation stated by Brand on the role of the courts in enforcing socioeconomic rights is in line with section 8(2)-(3) of the Constitution, when it comes to the application and enforcement of the rights in the Bill of Rights. ${ }^{16}$

The case of Treatment Action Campaign $v$ The Minister of Health, ${ }^{17}$ serves as a fundamental and instrumental case relating to the provision of section 27 of the Constitution. In this case, the applicants sought an order against the Minister of Health and the health authorities of all nine provinces, except for the Western Cape. The order, which they claimed, was to compel the minister and all health authorities in the eight provinces to implement an effective national programme to prevent or reduce mother-to-child transmission of the HIV/AIDS virus, which would include the dispensing of Nevirapine to pregnant women who are HIV positive, and to their babies. Nevirapine is described as an antiretroviral drug that can prevent or inhibit the spread of HIV. ${ }^{18}$ The applicants in this case described to the court the alarming rate of mother-to-child transmission and the impressive reduction that might be achieved by administration of the drug. ${ }^{19}$ It was claimed in court that a single dose of the drug can reduce this form of transmission by 50 per cent, but this allegation was disputed by the respondents who maintained that the success rate was probably considerably lower. ${ }^{20}$ The respondents further contended that immediate implementation of

15 Brand "Introduction to Socio-economic Rights in the South African Constitution" in Brand and Heyns (eds) Socio-economic Rights in South Africa (2005) 1.

$16 \mathrm{~S} 8(2)$ of the Constitution states that a provision in the Bill of Rights binds a natural and a juristic person, if and to the extent that it is applicable taking into account the nature of the right and the nature of the duty imposed by the right. S 8(3) of the Constitution of the Republic of South Africa, 1996 states that when applying a provision of the Bill of Rights to a juristic or a natural person in terms of subsection 2 a court, (a) in order to give effect to a right in the Bill of Right must apply, or if necessary develop, the common law to the extent that legislation does not give effect to that right; and (b) may develop rules of the common law to limit the right, provided that the limitation is in accordance with section 36(1). It is important to further take into account the fact that socio-economic rights are not only confined to the prerogatives of the legislature, executive and the judiciary. These rights can also be enforced through Chapter Nine institutions, which are established by the Constitution and support democracy, this includes the Human Rights Commission and the Public Protector that are both dealing with significantly the protection and enforcement of socio-economic rights. Section 184 of the Human Rights Commission Act, sets out the main functions of the Commission, which are as follows: (a) to promote respect for human rights and a culture of human rights; (b) to promote the protection, development and attainment of human rights and; (c) to monitor and assess the observance of human rights in the Republic.

72002 (4) BCLR 356 (T).

18 TAC $v$ The Minister of Health supra 357.

19 lbid.

20 TAC $v$ The Minister of Health supra 358-359. 
antiretroviral treatment in these cases would be impossible because of insufficient financial resources. ${ }^{2}$

Judge Botha in the High Court came to the conclusion, in respect of section 27 of the Constitution, that a countrywide prevention programme of this kind is an ineluctable obligation of the state. ${ }^{22}$ Moreover, Nevirapine can be affordable if the programme is properly planned. What was required, in the opinion of the court, was a plan that moved towards comprehensive coverage. The court accordingly made an order to this effect. ${ }^{23}$ The court made it clear that to order immediate roll out of the drug would be impossible and not practical, and as a result of this view, the court ordered the respondents to report back to it within three months with regard to the status of planning for the roll out of the drug. In this case, the court ruled in favour of the applicants. ${ }^{24}$ The Constitutional Court confirmed this decision of the High Court, ${ }^{25}$ as it reasoned that government policy, which provides for the availability of the Nevirapine drug in only certain areas of public hospitals, was inflexible and unconstitutional. Government was ordered to roll out the Nevirapine drug nationally for the purposes of preventing mother-to-child transmission of $\mathrm{HIV}^{26}$

Furthermore, section 27(2) of the Constitution provides that government must take reasonable legislative and other measures within its reasonable resources, to achieve the progressive realisation of each of these rights. What constitutes reasonable resources will be determined on the basis of the facts of each case. Despite the fact that the right to access to health care is constitutionally enshrined, it is still important to note that considerable inequalities exist in facilitating health care. These inequalities are largely caused by the discrepancies found in health resources and barriers to access health care services, such as vast distances, high travelling costs from rural areas, long queues and disempowered patients. ${ }^{27}$ For example, in Soobramoney $v$ Minister of Health, KwaZulu-Natal, ${ }^{28}$ the court dealt with the issue of unavailability of health services in the circumstances of a patient who was suffering from kidney failure, but was unfortunately denied treatment in the hospital. The conduct of the hospital was justified due to the lack of resources. This case will be discussed further in-depth later on in the paper.

\section{PUBLIC AND PRIVATE HEALTH CARE IN SOUTH AFRICA}

In South Africa, like most developing countries, the provision of health services is divided into two forms. There is a private health care sector and a

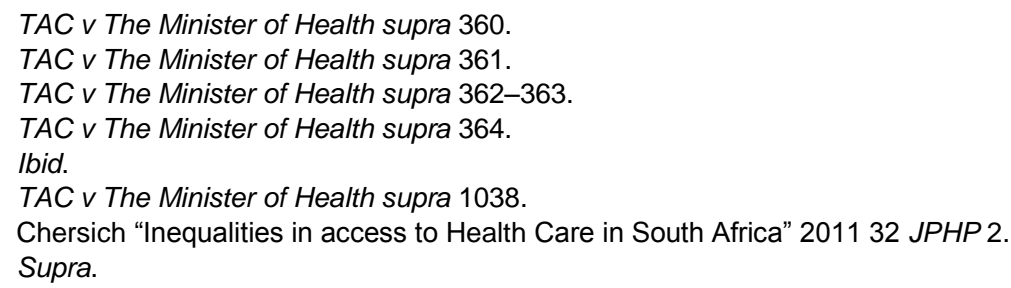


public health care sector, which co-exist. These two systems of health treatment were established during the apartheid era, and are still sustained in modern-day democratic South Africa. ${ }^{29}$ In order to understand the two systems of health care, it is important to consider a brief history in relation to how these two systems of health care were formed during the apartheid era. During the apartheid era, the quality and nature of health care services was based on three factors; which were race, location and income. ${ }^{30}$ Homelands were formed with the aim of formally separating people into different areas; and thus the same principle was applied to health care services, which were inadequate and poorly administered to the majority of black people in the homelands. ${ }^{3}$

During this period, the church played a significant role in the administration of health services to the majority of the people, due to the failure of the then government in providing health care services to the people in the public sector setting. ${ }^{32}$ The formation of the private sector came into existence as a result of the economic downturn and the pressure which was placed on the government by the medical industry, and which resulted in the government having to regulate the health sector. ${ }^{33}$ Through the regulation of the health sector, the private health sector was born as an institution of health services. Before delving into how the treatment of cancer is effected in South Africa, having a better understanding of how the two health care systems really work and how they contribute to the social and economic wellbeing of the people of South Africa is important.

\section{Private health care services}

It is estimated that only 15 per cent of the South African population makes use of private hospital treatment. ${ }^{34}$ In private hospitals, all cancer and other health related treatments are found to be effective and functional. Such efficiency and effectiveness is being achieved by means of readily available drugs and the presence of state of the art treatment machines. ${ }^{35}$ Private health care is accessed by people who have insurance or medical aid funding, and those who can afford to pay for it directly from their own pockets. ${ }^{36}$ Private health treatment, when compared with the public health treatment; accounts for the largest share of total health financing, which comprises of medical aid schemes and private out of pocket payments made

29 Beck "Health Policy, Health Services, and Cancer Pain Management in the New South Africa" 199917 JPSM 17.

30 Mclntyre, Church and Mello "The Health and Health System of South Africa: Historical Roots of Current Public Health Challenges" 2009374 Lancet 817.

31 Tollman and Kautzky "A Perspective on Primary Health Care in South Africa" 20082 SAHR 20.

32 Tollman and Kautzky 20082 SAHR 21.

33 Naylor "Private Medicine and the Privatization of Health Care in South Africa" 198811 Soc Science Med 1153.

34 Reynolds "Private Hospitals used by a Fraction of the South African Population" 17 May 2013 Mail and Guardian 5.

35 Reynolds 17 May 2013 Mail and Guardian 6.

36 Chersich 201132 JPHP 102. 
by patients. ${ }^{37}$ Private health treatment is generally regarded as the best in the country and is seen to be effective with regard to cancer treatment. ${ }^{38}$ However, there are challenges in this health system seeing as it is generally expensive to access, and thus is not easily accessible to impoverished persons who need the quality of care offered in private institutions. ${ }^{39}$ As a consequence, some medical aid schemes are not willing to pay for the treatment of cancer in private institutions, due to its expensive nature. One case in point is that of a woman who died in 2007 of breast cancer because her medical fund, Global Health, refused to pay for her treatment. ${ }^{40}$

Section 27 of the Constitution, also binds private hospitals to provide medical treatment to patients, in cases of an emergency situation. In addition, section 5 of the National Health Act 61 of 2003 supports the position that both private and public health establishments cannot deny anyone emergency medical treatment. ${ }^{41}$ Pieterse argues that the Constitutional obligation, which is placed on both private and public hospitals to provide emergency medical treatment, is a direct and immediate entitlement. ${ }^{42}$ The question as to what constitutes emergency treatment has been left open by the Constitution and has had serious financial implications for private hospitals, as they are obliged to render emergency medical treatment to people who cannot guarantee the necessary payment. ${ }^{43}$ Since

37 Akazili and Ataguba "Health Care Financing in South Africa: Moving towards Universal Coverage" 201028 CEM 75.

38 Akazili and Ataguba 201028 CEM 75.

39 Akazili and Ataguba 201028 CEM 76.

40 See Adams "Judicial and Regulatory Interpretation of the Employment Rights of People with Disabilities" 13 May 2007 Star 1. The Competition Tribunal commented on the state of health care in South Africa and how the private health care system has become a lucrative business. "The provision of adequate health care to all the citizens of the country is clearly an important plank in the government's efforts to tackle poverty and inequality. High and middle income earning South Africans (and this would include a significant proportion of those in employment) receive health care through South Africa's sophisticated private health care system comprising the full gamut of general practitioners, specialists, hospitals and pharmacies. Private health care is funded by an array of medical schemes serviced by the administration companies, data processing companies and managed care companies that are an integral part of South Africa sophisticated "first world" private health care system. However, majority of the population (and this includes a significant number of those in the lower reaches of formal employment) rely on the public health system for meeting its needs. The reality and possibly the only agreed certainty in the fraught debate surrounding the provision of health care in South Africa; is that the private health care systems, and most notably, although not exclusively, the private hospital network, is characterised by significant excess capacity, while on the other hand, the public health care system is simultaneously resource-constrained and increasingly unable to cope with the demands made of it. A major thrust of the government's efforts to improve health care provisioning is thus to utilise the excess capacity in the private health care system, to reduce the demands on the public health care system, to move a strata of those presently reliant on public health care over to the private health care system." Medicross Healthcare Group (Proprietary) Limited and Prime Cure Holdings (Proprietary) Limited, Case No.11/LM/Mar05 par 52 and 53

4161 of 2003.

42 Pieterse "Enforcing the Right not to be Refused Emergency Medical Treatment: Towards Appropriate Relief" 200718 Stell LR 75.

43 Pieterse "Legislative and Executive Translation of the Right to have Access to Health Care Services" 201010 Law Democracy and Development 243. 
the question of what constitutes emergency medical treatment has been left open by the Constitution, it is assumed to be a question of fact, which will be decided on a case-by-case basis. However, in the landmark case of Soobramoney $v$ Minister of Health (KwaZulu-Natal), ${ }^{44}$ which is discussed indepth below; the court defined emergency medical treatment as a "sudden catastrophe which calls for immediate attention". ${ }^{45}$ The broad and flexible nature of this definition surely makes it an acceptable definition, because it caters for all forms of health emergencies without excluding the other.

Due to the seriousness of the obligation to provide emergency medical treatment, and the inconsistencies of some private hospitals in implementing and realising this socio-economic right to health care; specific legislation was enacted, which deserves mention. Item $3(\mathrm{~b})$ of the Schedule to the Promotion of Equality and Prevention of Unfair Discrimination Act 4 of 2000 reinforces the obligation imposed on private hospitals to render emergency treatment to a patient, by prohibiting the discriminatory refusal of emergency treatment. As a consequence, cancer patients in an emergency situation can be admitted to a private hospital to receive treatment; and unfortunately, that particular hospital will be able to bill the patient for the services which they have rendered without taking into account whether the patient can afford the bill or not.

The Hospital Association of South Africa was established as a solution to the problem imposed by its members. This association has incorporated a draft code of ethics for private hospitals across the country. ${ }^{46}$ In the draft code of ethics for private hospitals, an emergency treatment is defined as "treatment that is necessary to stabilise an emergency medical condition". ${ }^{47}$ The code requires private health establishments to render such treatment ethically without any form of discrimination and subject to reasonable compensation. This definition of emergency medical treatment as provided for by the Hospital Association of South Africa is in line with the definition that was provided by the court in the Soobramoney case because they both cater for all forms of health emergencies without excluding other forms.

\section{Public health care services}

Although public health treatment in South Africa is administered to 75 per cent of the population, which comprises urban and rural areas, ${ }^{48}$ it is chronically underfunded and understaffed. The public health treatment of cancer and other related illnesses is characterised by inadequate treatment facilities, less or unavailable drugs, crowding of patients, unqualified staff

\footnotetext{
Supra 1697.

45 Soobramoney $v$ Minister of Health supra par 36.

46 Proposed Code of Ethics for Private Hospitals - Hospital Association of South Africa (HASA) Private Hospital Review 2008: Examination of Factors Impacting on Private Hospitals (2008) 67.

47 Clause 1 of the Proposed Code of Ethics for Private Hospitals - Hospital Association of South Africa (HASA) Private Hospital Review 2008: Examination of Factors Impacting on Private Hospitals (2008) 67.

48 Falkson and Beck "Prevalence and Management of Cancer Pain in South Africa" 200194 Pain 76.
} 
and abuse of patients by staff. ${ }^{49}$ The public health treatment mechanism can be viewed as the exact opposite of the private health treatment in the country. For example, breast cancer patients have to wait for weeks before undergoing surgery in the Groote Schuur Hospital situated in Cape Town, ${ }^{50}$ due to the unavailability of funds from the National Department of Health. Not enough staff is available and in addition to that; defective, as well as old equipment is used to assist patients, which was seen to be the case in KwaZulu-Natal recently. ${ }^{51}$ These mentioned obstacles, in addition to the physical pains that cancer patients have to go through; cause a lot of distress for cancer patients and their families, and are unfortunately beyond their control. ${ }^{52}$

Proper measures need to be taken to avoid or prevent the government from disregarding the realisation of the right to access to health care for all people. However, this has proven to be an impossible task in the case where the cervical cancer screening process has already perpetuated inequality in regards to the availability of such facilities. ${ }^{53}$ This is because cancer screening facilities are available for some people but not for everyone in the country. For instance, women in rural areas who live far away from clinics are deprived of this service; while those who stay in cities and urban areas that are situated nearer to hospitals and clinics will always have access to these health services. This amounts to unfair discrimination in terms of section $9(1)$ of the Constitution; either directly or indirectly to those women who stay in the rural areas that are deprived of services, ${ }^{54}$ and their right to access to health care services as provided for in terms of section 27 of the Constitution is surely compromised in this regard.

Around 3800 women, who mostly rely on public health treatment, die of cervical cancer every year in South Africa. ${ }^{55}$ This shows that there is a problem in the public health treatment system, which calls for concern. The Cancer Association of South Africa (CANSA) has stressed the importance of making screening programmes widely available for women for purposes of early detection of any cancer in order to reduce the number of deaths, which are caused by cancer. ${ }^{56}$ Patients making use of public hospitals may compel the hospital to provide treatment for them; but this may be limited, as the state will provide the treatment based on its available resources in accordance with section 27 of the Constitution.

49 Chersich 201132 JPHP 103.

50 Smetherham "Breast Cancer Patients face Medical Challenges in Public Hospitals" 17 October 2002 Cape Times 3.

51 Smetherham 17 October 2002 Cape Times 4.

52 Patijnet "High Prevalence of Pain in Patients with Cancer in a Large Population-Based Study in the Netherlands" 2007132 Pain 312.

53 Denny, Kuhn and Batra "Utilisation and Outcomes of Cervical Cancer Prevention Services among HIV-Infected Women in Cape Town 2010100 SAMJ 39.

$54 S 9(1)$ of the Constitution states that everyone is equal before the law and has the right to equal protection and benefit of the law.

55 Express "More Services needed to fight Cancer" 200623 University of Free State 8.

56 Express 200623 University of Free State 9. 


\section{Soobramoney $v$ Minister of Health (KwaZulu-Natal) 1998 (1) SA 765 (CC)}

This case involved a patient who was in need of dialysis treatment on a weekly basis, as the patient was suffering from kidney failure and needed treatment to survive. ${ }^{57}$ The state argued that there were not enough facilities to offer this treatment as it was expensive. ${ }^{58}$ The state, however, rendered that it would provide treatment based on its available resources in order to preserve the life of the patient in question. ${ }^{59}$ The court further reasoned that the decision of the minister was made in good faith and through rational decision making which was found to be in the best interest of the public; and therefore did not warrant any interference by the court. ${ }^{60}$ The court ruled in favour of the minister and refused to compel the hospital to act in the manner in which the patient anticipated, but confirmed that the hospital in question acted on the basis of its available resources, in its provision of treatment; and as expected in terms of section 27 of the Constitution. ${ }^{61}$

Based on the provision of section 27(2) of the Constitution and the Soobramoney case, one can deduce that the right to access to health care as guaranteed in terms of section 27(1) of the Constitution is not absolute, in the sense that it is dependent on the availability of reasonable resources. ${ }^{62}$ As to what really constitutes reasonable resources is surely a question of fact and needs a precise definition. The vagueness of reasonableness in this context entails that a patient can lose his or her life in a public health establishment, without the hospital being held liable, therefore. The public health establishment can argue that it acted within the limits of its reasonable resources to save the life of the patient and thus can be justified in this respect. The aspect of reasonable resources in the provision of health services is a form of a qualified step to the provision of health services that needs urgent examination as to what it entails, and the effect it has on the overall right to health care services as provided for in the Constitution.

The first step in addressing the vagueness of the concept of reasonable resources as stated in section 27 of the Constitution is to adopt the position that was followed in the court case of Government of Republic of South Africa $v$ Grootboom. ${ }^{63}$ In this case, the standard of reasonableness was

\footnotetext{
Soobramoney $v$ Minister of Health supra 1697.

Ibid.

Soobramoney $v$ Minister of Health supra 1698.

Soobramoney $v$ Minister of Health supra 1701.

Soobramoney $v$ Minister of Health supra 1697.

62 S 36(1) of the Constitution states that the rights in the Bill of Rights may be limited only in terms of the law of general application to the extent that the limitation is reasonable and justifiable in an open and democratic society based on human dignity, equality and freedom, taking into account all the relevant factors including, the nature of the right; the importance of the purpose of the limitation; the nature and extent of the limitation; the relationship between the limitation and its purpose and less restrictive means to achieve the purpose.

63 (CCT1100) [2000] ZACC 19; 2001 (1) SA 46; 2000 (11) BCLR 1169 (4 October 2000), in this case the facts involve the eviction of informal residents in a private owned land which was reserved for the construction of low costs houses. The residents opposed their eviction by the government on the basis that the government was obliged to provide it with alternative or temporary shelter as enshrined by the Constitution, until they acquired permanent accommodation with their off springs. The court held that the government was
} 
adopted to test the relevant legislation regarding its fulfilment or realisation of socio-economic rights. The case is relevant for this discussion since the right to have access to health care services is also a socio-economic right and forms the point of discussion at present. According to the court, any measures, which are adopted with the aim of fulfilling socio-economic rights, ought to encompass a standard that is reasonable in both their conception and implementation. ${ }^{64}$ This simply means that there must be a clear allocation of tasks and responsibilities to different stakeholders in government; and appropriate financial and human resources have to be made available in order to realise socio-economic rights. This reasoning of the court, regarding the duty of government to fulfil socio-economic rights, is in line with the proclamation of the United Nations Committee on Economic, Social and Cultural Rights (CESCR) of which South Africa is a member and to which South Africa is a party. ${ }^{65}$ The proclamation states that in order for a state party to be able to attribute its failure to meet at least its minimum core obligations to a lack of resources, it must demonstrate that every effort has been made to use all resources that are at its disposition in an effort to satisfy, as a matter of priority, those minimum obligations. ${ }^{66}$

The most important aspect, which the court highlighted in the Soobramoney case, is that the legislation or policy, aimed at the realisation of socio-economic rights, must be transparent and communicated effectively to all the parties concerned. It should be effectively implemented without confusion, however; this is unfortunately not the current state of affairs particularly in our public health system. ${ }^{67}$ Pieterse argues that the nonfulfilment of the right to access to health care services for patients in public health care is not only attributed to inadequate legislation and health policy; but is also due to failures to translate and interpret the right to its correct meaning and aim. ${ }^{68}$ Pieterse's view is correct as we have seen this problem arise in the context of determining what constitutes reasonable resources as provided for in terms of section $27(2)$ of the Constitution. ${ }^{69}$

The major challenge in both private and public hospitals in South Africa is the shortage of qualified staff. This challenge results in a frustration of the

obliged to provide temporary or alternative shelter, on demand, to children and parents and in instances where parents are unable to accommodate their own children. The court further reasoned that this duty by the government to provide shelter to the people is independent and the state must take reasonable legislative and other measures within its disposal to realise this goal. In this case the court concluded by outlining that the state was obliged to provide temporary accommodation to the evicted dwellers without taking into account the aspect of availability of resources; this was due to the fact that the was a crisis and an emergency. The appeal court however, was in disagreement with the court a quo when it came to this decision.

64 Government of Republic of South Africa v Grootboom supra 1169

65 International Covenant on Economic, Social and Cultural Rights (CESCR) adopted and opened for signature, ratification and accession by General Assembly Resolution $2200 \mathrm{~A}$ (XXI) of 16 December 1966 and came into force on 3 January 1976 in accordance with article 27 of the United Nations.

66 Ibid.

67 Pieterse 201010 Law Democracy and Development 250.

68 Ibid.

69 Pieterse 201010 Law Democracy and Development 252. 
relationships between patients and medical personnel. ${ }^{70}$ In the context of cancer, the shortage of staff will result in the unavailability of necessary resources and support to deal with the demands of the oncology unit. ${ }^{71}$ The problem of shortage of staff is not only a challenge in South Africa, between the private and public health care centres; but it affects the entire African continent and it has become a major factor in crippling the health system of the continent. ${ }^{72}$

In Africa, 10000 medical professionals, graduate each year, but within five years, about half of them leave for Europe in search of greener pastures. ${ }^{73}$ Most African graduates leave due to low salaries, restricted career development options, and work overload, which they experience in Africa. ${ }^{74}$ Development in the labour force, which deals with cancer, is required in Africa, and needs proactive efforts and commitment of each country. Providing career counselling and mentorship programmes to students in medical schools and professional institutions can do this. Offering incentives to generate an interest and commitment among young medical professionals in order for them to stay in Africa and not go abroad is also a mechanism that may possibly alleviate the problem.

\section{CANCER TREATMENT IN BOTH PUBLIC AND PRIVATE HEALTH SYSTEM}

The composition of private and public health systems in the treatment of cancer and other health deformities is not only a problem in South Africa but is also a global issue. In the United Kingdom to which its legal system has influenced the South African legal system to a lesser or greater extent, patients have reported bad experiences and treatment in the public health domain, compared to the private health sector where things are running effectively. ${ }^{76}$ The justification for the problem raised by the government was that public health establishments have to treat a lot of patients, and yet there are inadequate facilities for the effective administration of treatment to

70 Venter and Botha "Cancer Treatment in South Africa: A Narrative Literature Review" 2012 22 JPA 462

71 Ibid.

72 Venter and Botha 2012 JPA 464

73 Adewole "Challenges and Opportunities in Cancer Control in Africa: A Perspective from the African Organisation for Research and Training in Cancer" 201314 Series 147.

74 Adewole 201314 Series 147. Further, the shortage of medical practitioners has put a lot of pressure in the medical industry, and this is evident by the fact that training medical students, work excessive hours in order to meet or breach this shortfall. This has resulted in dire consequences for these medical practitioners, at some point losing their lives due to the pressure and fatigue that comes with the profession. Eg, in Cape Town, recently a medical student was involved in an accident due to fatigue and she lost her life due to working long hours. This has resulted in the government to provide new guidelines with regard to the working conditions of these medical practitioners who are still in training, and this proposed plan will start to be implemented as from next year. eNCA "SA junior doctors call for new regulations on working hours" https://www.enca.com/south-africa/sa-junior-docs-call-fornew-regulations-on-working-hours (accessed 2016-10-23).

75 Adewole 2013 Series 147.

76 Lyratzopoulos "What explains Worse Patient Experience in London? Evidence from Secondary Analysis of the Cancer Patient Experience Survey" 20144 BMJ OPEN 1. 
patients. ${ }^{77}$ This is also the position in South Africa, as it has been stated that public health care caters for about $75 \%$ of patients, which is the majority of the population. ${ }^{78}$ The public health care system surely needs an urgent facelift in order for it to be well equipped to give quality treatment to patients, as well as for purposes of assisting in upholding the preservation of the right to life as enshrined in section 11 of the Constitution. ${ }^{79}$ The public health care sector is the most important sector in which the government plays a big role in preserving a number of fundamental human rights and thus should be improved to become the best avenue of health care services in South Africa.

It is argued that cancer is best treated in the private health care sector when a patient has medical insurance or financial means to access the best medical treatment. ${ }^{80}$ The circumstances are very unfortunate for the millions of people who rely on the public health care system for treatment because it is overburdened and poorly administered. The treatment of cancer involves screening tests for early detection of cancer, chemotherapy, radiation therapy and surgery as well as psychological assistance, which the patient often needs and is costly to acquire. ${ }^{81}$ Cancer patients must have the money or medical insurance in order to get effective treatment; which means that only a few people who rely on the public health care will get effective treatment. However, this is of no consolation to many others who die of this disease every year and is indeed a cause for concern for the government.

Based on the abovementioned factors, it is argued that cancer is a disease better dealt with by the rich and sophisticated as they are the ones who are able to seek the necessary treatment to survive from cancer, and they are commonly more knowledgeable and educated on the topic of cancer. ${ }^{82}$ On the African continent, the challenges of the public health care sector, which stem from the high costs of cancer treatment, are caused by a lack of political will, ignorance of the government and international funding agencies that ought to offer support to cancer patients. ${ }^{83}$ In view of the assessment of cancer treatment in Africa as a whole, Emerson's idea that the first wealth of any nation is health has been compromised due to the poor administration of cancer treatment. ${ }^{84}$ In accordance with Emerson's argument, if a country is healthy, then it can achieve its goals of addressing socio-economic challenges, as the latter will not be possible if a country is crippled by a disease such as cancer.

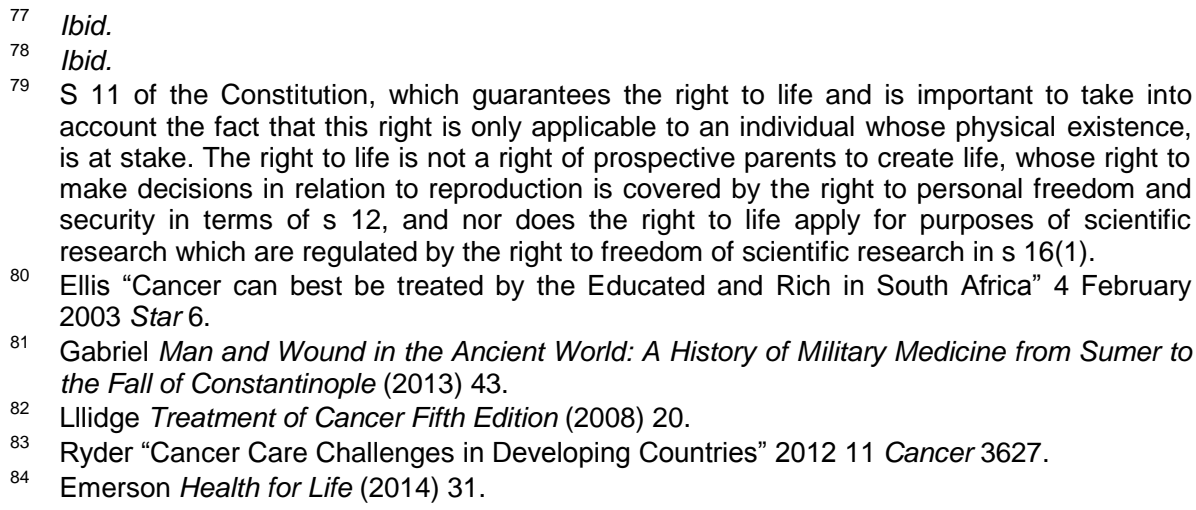
account the fact that this right is only applicable to an individual whose physical existence, is at stake. The right to life is not a right of prospective parents to create life, whose right to make decisions in relation to reproduction is covered by the right to personal freedom and security in terms of $s 12$, and nor does the right to life apply for purposes of scientific research which are regulated by the right to freedom of scientific research in s 16(1).

80 Ellis "Cancer can best be treated by the Educated and Rich in South Africa" 4 February 2003 Star 6.

81 Gabriel Man and Wound in the Ancient World: A History of Military Medicine from Sumer to the Fall of Constantinople (2013) 43.

82 Lllidge Treatment of Cancer Fifth Edition (2008) 20.

83 Ryder "Cancer Care Challenges in Developing Countries" 201211 Cancer 3627.

84 Emerson Health for Life (2014) 31. 
In Africa, the competing burdens of diseases such as HIV/AIDS, tuberculosis and malaria adversely impact the attention given to cancer in regard to both political and public health planning. ${ }^{85}$ The lack of attention given to cancer and its treatment mechanisms has resulted in cancer being one of the deadly silent killers on the African continent. ${ }^{86}$ The current lack of decisive political will to address cancer on the African continent is attributed to similar results of lack of focus, which was initially accorded the HIV/AIDS pandemic by governments in the continent around the 1990s. ${ }^{87}$ Patients suffered and millions of lives were lost as a result of the HIV/AIDS pandemic. This was because African leaders were engaged in a non-scientific debate on whether HIV caused AIDS, refuting affirmative scientific evidence. ${ }^{88}$ The major contributing factor to the lack of decisive leadership regarding HIV/AIDS was the issue of denial. Cohen argues that denial is the common thread, which causes people, organisations, governments and societies to avoid fully acknowledging a reality when they encounter information that is disturbing or threatening to life as they know it. ${ }^{8}$

According to this reasoning, it is very clear that denial is used as a coping mechanism to deal with disturbing emotions, such as guilt or anxiety, that come with the realisation of unthinkable or unbearable diseases like HIV/AIDS and cancer. ${ }^{90}$ To prevent the continual unfortunate loss of lives, and to avoid the perpetuation of the mistake that was made in Africa about HIV/AIDS due to its denial, ${ }^{91}$ cancer advocates and lobby groups such as Cancer Association of South Africa must take critical lessons from their HIV/AIDS counterparts and find strategies to engage the government in similar interactions to facilitate the development of a focused, sustainable and scalable national strategic plan for cancer on the basis of grounded and well-researched evidence. ${ }^{92}$

A useful tool that can be employed for the treatment of cancer in South Africa is the comprehensive multi-disciplinary and multi-sectorial approach to HIV/AIDS, which President Zuma introduced. ${ }^{93}$ This presents an opportunity for the national HIV/AIDS and cancer political advocates to partner up as the two diseases in some instances occur concurrently in the same patient. It would be highly cost effective to develop and implement integrated research and treatment plans. ${ }^{94}$ Such intervention will surely assist in dealing with the

\footnotetext{
Ryder 201211 Cancer 3628

Parker and White "Oesophageal Cancer: An Overview of a Deadly Disease" 20071 AAS 1.

Patterson The African State and the AIDS Crisis (2005) 240.

Ibid.

Cohen The Elementary Forms of Denial: In States of Denial (2001) 3.

90 Mackintosh "The Politicisation of HIV/AIDS in South Africa: Responses from the Treatment Action Campaign and South African Government, 1994-2004" 2009204 CSSR 8.

91 Patterson The African State and the AIDS Crisis 242.

92 Lynch Hospice and Palliative Care in Africa: A Review of Developments and Challenges (2006) 516.

93 Asante-Shongwe "Perspective of an Advocate-political Advocacy in African Cancer Dialogue" 20138 Proceedings 2.

94 Lynch Hospice and Palliative Care in Africa: A Review of Developments and Challenges 517.
} 
effective and necessary treatment of cancer that is urgently required in South Africa and in Africa as a whole. ${ }^{95}$

The complex and expensive nature of cancer treatment necessitates closer collaboration between the two spheres of health care systems in order to deal with cancer cases. The collaboration, which takes place between these two spheres of health care service systems in ensuring that health care services are provided to all people, despite their socio-economic standing, is what Goudge correctly describes as the "public-private mix". Collaboration may take the form of the private health care system teaching the public health care system a few things, and vice versa. This can also take the form of a bilateral relationship between the two spheres of health care. ${ }^{97}$

Furthermore, the recently proposed National Health Insurance is a measure that is aimed at closing the gap between the two spheres of health services, by ensuring that access to health care is a social right, which is not dependent on the economic standing of the individual. ${ }^{98}$ The National Health Insurance proposal issued by the government of South Africa is in line with the goal of the World Health Organisation (WHO) drive for universal international health care in developing countries. ${ }^{99}$ Whether the proposed National Health Insurance will succeed is a question of fact and time. The National Health Insurance proposal has received wide criticism from academics, political parties and private institutions due to its exclusion of the private health care sector; and the huge financial strain it will have on the fiscal position of the country. ${ }^{100}$ For purposes of this study, the debate as to whether the National Health Insurance scheme will be a success is not considered, however, for the sake of a comprehensive understanding of the state of the health care system in our country, it is important to outline the interventions of government in ensuring that all people have a social right to health care services, despite their economic status.

Coming up with an effective treatment mechanism for cancer in the African continent will not be an easy task to fulfil. In order to create an

95 Immunology "The Multi-disciplinary and Multi-sectoral Approach to fight HIV in South Africa" 22 November 2006 Business Day 5.

96 Goudge Public-Private Mix (2000) 5.

97 McCready "How Can Diagnostic Assessment Programs be implemented to Enhance InterProfessional Collaborative Care for Cancer?" 20149 BioMed Central 1.

98 The National Health Insurance (NHI) White Paper outlines the aim and purpose of the National Health Insurance. This white paper outlines the fact that South Africa is in the process of introducing an innovation of health care financing that will have far-reaching consequences on the health of South Africans. The National Health Insurance commonly referred to as the $\mathrm{NHI}$ will ensure that everyone has access to appropriate, efficient and quality health care services. It will be phased in over a period of 14 years, and this will entail major changes in the service delivery structures, administrative and management systems. The $\mathrm{NHI}$ is intended to bring about reform that will improve service provision. It will promote equity and efficiency to ensure that all South Africans have access to affordable, quality health care services regardless of their socio-economic status.

99 World Health Organisation (WHO) The World Health Report: Primary Health Care - Now More than Ever (2008) 20.

100 Surender "The Drivers of Universal Health Care in South Africa: The Roles, Ideas, Institutions and Actors" 201419 UNRISD 14. 
effective mechanism that can beat cancer across borders; partnerships will have to emerge and bridges will have to be built across countries, economies and professions so as to establish joint efforts that are aimed at making that mechanism effective. ${ }^{101}$ A strategic cancer control mechanism will have to be developed in Africa, in order to build on what works and what is unique in the region for purposes of cancer management. ${ }^{102}$ Such a mechanism would have to ideally be situated within strong, robust and sustainable health care systems that offer quality health care to all people, irrespective of their social or economic standing. However, to achieve this will demand financial investment, particularly for cancer and new leadership, critical thinking, and understanding of cancer.

\section{CONCLUSION}

In conclusion, is important to note and emphasize that the right to access to health care is a social right and not an economic right, which is, unfortunately, the case in South Africa and across the globe. This paper has outlined how cancer patients, in this case, are not receiving the necessary treatment and these patients rely on the public health care system. For the effective realisation and implementation of this right to the millions of people who do not have the financial muscle to access health care, collaborations between the private and public health sectors are eminent, as well as necessary. The high costs of medical treatment, which prevents patients suffering from chronic illnesses like cancer and who do not have the financial muscle to access health care, currently requires the attention of the government when it comes to the regulation of the health sector and to realise this social right as a basic human right the way it was enshrined in the Constitution.

\footnotetext{
Asante-Shongwe 20138 Proceedings 2

Ibid.

103 Adewole 2013 Series 142.
} 